IP Periodica Polytechnica Civil Engineering

60(3), pp. 361 369. 2016

DOI: $10.3311 /$ PPci.7732

Creative Commons Attribution (1)

RESEARCH ARTICLE

\section{Allowable Deformation Prediction for Surrounding Rock of Underground Caverns Based on Support Vector Machine}

Ma Cong, Tan Yuehu, Li Erbing, Yang Meng, Duan Jianli

Received 27-09-2014, revised 03-03-2015, accepted 14-04-2015

\section{Abstract}

This paper presents a novel allowable deformation prediction model of surrounding rock based on support vector machine (SVM). The engineering rock mass classification is subdivided based on the national standards Standard for Engineering Classification of Rock Masses in order to get more accurate physicalmechanical parameters. Using the developed parameters, 100 sets of multi-factors and multi-levels orthogonal experiments are designed, which are simulated with two-dimensional numerical models established based on ABAQUS. 100 groups of learning samples and 9 samples of random inspection are obtained. The prediction model has been established from the study of learning samples based on LibSVM. Using this model, 9 samples of random inspection and 9 engineering examples are predicted and the prediction accuracy is good compared with their actual values. It is indicated that this model can meet the initial support design requirements of underground caverns well. The novel model has the advantages of convenience, rapidity, and reliability.

\section{Keywords}

allowable deformation · engineering rock mass classification . orthogonal experiment $\cdot$ prediction $\cdot$ support vector machine . underground caverns

\section{Ma Cong}

Xiangyang Noncommissioned School, Military Economy Academy, Xiangyang,441118, China

e-mail: ma_cong0301@126.com

Tan Yuehu

Li Erbing

Yang Meng

Duan Jianli

College of Defense Engineering, PLA University of Science and Technology, Nanjing, 210007, China

\section{Introduction}

Deformation of surrounding rock has always been a key problem during the construction of underground caverns. In the recent years, many studies focusing on time series prediction have been carried out to study the deformation prediction of surrounding rock $[1-3]$. By studying the laws of surrounding rock deformation changes with time on a measuring point of a crosssection in underground caverns, the deformation of surrounding rock is predicted in future. However, the study on maximum deformation of surrounding rock of underground caverns has gained less attention. Li [4] studied the general relationship between displacement and surrounding rock classification using the typical analogy analysis method on the basis of the collected 59 engineering projects. Yang [5] proposed an empirical formula to predict the deformation of surrounding rock, which was based on rock quality index value, cavern depth and size. However, most of the engineering projects in these research based on had been made initial support. The support type and tectonic stress field are different for each project. Meanwhile, the mechanics parameters of surrounding rock with the same classification differ greatly. Despite under the same conditions of rock classification, cavern buried depth and size, there is still great difference for surrounding rock deformation, about nearly 10 times. Furthermore, the representativeness of selected engineering projects has greater influence on the research results.

The maximum deformation of surrounding rock under the premise of no support and failure is defined as allowable deformation of surrounding rock. In other words, allowable deformation is the maximum displacement just before failure. At present, no enough studies on allowable deformation of surrounding rock has been carried out. Determination of allowable deformation is beneficial to choose the right support time and to ascertain reasonable reserved deformation value (between primary support and secondary lining). Moreover, it has important reference significance for the initial supporting design of underground caverns. Therefore, it is very essential to achieve the allowable deformation of surrounding rock quickly, conveniently, and accurately before support design.

Support vector machine (SVM) is a new general machine 
learning method, which was proposed by Vapnik in the $1990 \mathrm{~s}$ based on structural risk minimization principle of statistical learning theory [6,7]. It has achieved widespread application because of its good learning promotion and nonlinear mapping ability $[8-10]$. In order to overcome the influence of supporting type, tectonic stress, rock mass classification and measurement error, we introduced a novel allowable deformation prediction model for surrounding rock of underground caverns based on SVM. 100 groups of orthogonal experiment models was established and the numerical simulation experiments were conducted to obtain 100 learning samples so that the SVM prediction model of allowable deformation was established.

\section{SVM prediction model}

\subsection{Influence factors of allowable deformation}

The main influence factors of allowable deformation of surrounding rock include the size of caverns, the quality of surrounding rock, the space position and the construction factor. This research is based on the following assumptions:

1 Construction factor is not considered. In practical engineering, the construction factor is a human factor. It will not lead to large deformation of surrounding rock, as long as construction is carried out according to the optimal construction plan and control. Meanwhile, construction factor is difficult to quantify.

2 Only the role of gravity stress field and its horizontal component are considered. Large tectonic stress situation is not considered especially under the condition of horizontal stress greater than vertical stress. The spatial location of underground caverns involves the ground pressure problem and stress field. The tectonic stress has large uncertainty, and it is difficult to express in functional form.

Therefore, three influence factors are taken into consideration, which are rock mass classification, cavern buried depth and cavern size. The mapping relationship between allowable deformation and three above influence factors is established.

\subsection{Support vector machine prediction model}

Support vector machine has a strict theoretic basis, and also can solve the practical problems of small samples, nonlinearity, high dimension and local minimum point. Meanwhile, it has good learning promotion and nonlinear mapping ability. Support vectors in SVM are obtained by solving a convex quadratic optimization problem, which can ensure that the local optimal solution is the global optimal one. A brief introduction of support vector machine function fitting problem is introduced as following [11]. SVM function fitting is to perform a regression of the samples in area by using support vector machine. Thereby, the mapping function of the area is determined. Then the values of unknown samples of this area are calculated according to the fitting function.
1) For linear regression problem: It is known that $D=$ $\left\{\left(\mathbf{x}_{\mathbf{i}}, y_{i}\right), i=1, \cdots, k, \mathbf{x}_{\mathbf{i}} \in \mathbf{R}^{k}, y_{i} \in R\right\}$. A function $f(x)=$ $\omega \cdot \mathbf{x}+b$ based on the training set $D$ is identified to approximate the unknown regression function, where $\omega$ and $b$ are parameters of the regression function. It is assumed that $k$ training samples in training set can be fitted by using linear function without error under the precision $\varepsilon$, namely

$$
\left\{\begin{array}{l}
y_{i}-\omega \cdot \mathbf{x}_{\mathbf{i}}-b \leq \varepsilon \\
\omega \cdot \mathbf{x}_{\mathbf{i}}+b-y_{i} \leq \varepsilon
\end{array} \quad i=1, \ldots, k\right.
$$

The regression estimation problem is defined as the risk minimization problem of a loss function. When using structural risk minimization principle for risk minimization, the minimizing functional for the optimal regression function is:

$$
\phi(\omega, \xi)=\frac{1}{2}\|\omega\|^{2}+C \sum_{i=1}^{k}\left(\xi_{i}+\xi_{i}^{*}\right)
$$

Where $C$ is a constant called penalty coefficient, which controls the degree of punishment when the sample beyond the error $\varepsilon ; \xi_{i}$ and $\xi_{i}^{*}$ are relaxation factors which are introduced in view of the acceptable fitting error. Now constraint condition is

$$
\left\{\begin{array}{c}
y_{i}-\omega \cdot \mathbf{x}_{\mathbf{i}}-b \leq \varepsilon+\xi_{i} \\
\omega \cdot \mathbf{x}_{\mathbf{i}}+b-y_{i} \leq \varepsilon+\xi_{i}^{*} \quad i=1, \ldots, k \\
\xi_{i} \geq 0 \\
\xi_{i}^{*} \geq 0
\end{array}\right.
$$

For the quadratic optimization problem above, Lagrange multipliers $\left(\alpha_{i}\right.$ and $\left.\alpha_{i}^{*}\right)$ are introduced to construct the Lagrangian functional, and the dual problem of the original problem is obtained in the following condition:

$$
\left\{\begin{array}{c}
\sum_{i=1}^{k}\left(\alpha_{i}-\alpha_{i}^{*}\right)=0 \quad i=1, \ldots, k \\
0 \leq \alpha_{i}, \alpha_{i}^{*} \leq C,
\end{array}\right.
$$

To maximize the objective function

$$
\begin{aligned}
& \operatorname{Max} W\left(\alpha, \alpha^{*}\right)=-\frac{1}{2} \sum_{i, j=1}^{k}\left(\alpha_{i}-\alpha_{i}^{*}\right)\left(\alpha_{j}-\alpha_{j}^{*}\right)\left(\mathbf{x}_{\mathbf{i}} \cdot \mathbf{x}_{\mathbf{j}}\right)+ \\
& +\sum_{i=1}^{k}\left(\alpha_{i}-\alpha_{i}^{*}\right) y_{i}-\sum_{i=1}^{k}\left(\alpha_{i}+\alpha_{i}^{*}\right) \varepsilon
\end{aligned}
$$

This is a typical convex quadratic optimization problem. By solving this problem, the SVM fitting function is obtained:

$$
f(\mathbf{x})=\sum_{i=1}^{k}\left(\alpha_{i}-\alpha_{i}^{*}\right)\left(\mathbf{x}_{\mathbf{i}} \cdot \mathbf{x}\right)+b
$$

where $\alpha_{i}$ and $\alpha_{i}^{*}$ are Lagrange multipliers. When $\alpha_{i}$ and $\alpha_{i}^{*}$ are not both zero, the sample is the support vector.

2) For nonlinear regression problem: Nonlinear mapping is used to map the input vector into a high dimensional feature space, in which the nonlinear problem can be solved by translating into a similar linear regression problem. Assuming that $\phi(x)$ 
is a nonlinear mapping, $K(u, v)$ is a symmetric function which satisfies the Mercer condition. Thus $K(u, v)=\phi(u) \cdot \phi(v)$ can be obtained. $K(u, v)$ is the kernel function. Kernel function is used to avoid the problem of "dimension disaster" in the high dimensional feature space. In addition, a kernel function of input space is applied to replace the inner product form of higher dimensional space. Thereby, the problem of high-dimensional calculation is solved in a skillful way. Hence, the problem of nonlinear regression optimization is translated into maximizing the objective function subjected to (4) as:

$$
\begin{aligned}
& \operatorname{Max} W\left(\alpha, \alpha^{*}\right)=-\frac{1}{2} \sum_{i, j=1}^{k}\left(\alpha_{i}-\alpha_{i}^{*}\right)\left(\alpha_{j}-\alpha_{j}^{*}\right) K\left(\mathbf{x}_{\mathbf{i}}, \mathbf{x}_{\mathbf{j}}\right) \\
& +\sum_{i=1}^{k}\left(\alpha_{i}-\alpha_{i}^{*}\right) y_{i}-\sum_{i=1}^{k}\left(\alpha_{i}+\alpha_{i}^{*}\right) \varepsilon
\end{aligned}
$$

Where $K$ is the kernel function. For a specific problem, the determination of the appropriate kernel function is the most important part of nonlinear regression. In this case:

$$
\omega=\sum_{i=1}^{k}\left(\alpha_{i}-\alpha_{i}^{*}\right) \phi\left(\mathbf{x}_{\mathbf{i}}\right)
$$

SVM fitting function can be expressed as:

$$
f(\mathbf{x})=\sum_{i=1}^{k}\left(\alpha_{i}-\alpha_{i}^{*}\right) K\left(\mathbf{x}, \mathbf{x}_{\mathbf{i}}\right)+b
$$

where $\alpha_{i}$ and $\alpha_{i}^{*}$ are Lagrange multipliers. When $\alpha_{i}$ and $\alpha_{i}^{*}$ are not both zero, the sample is the support vector.

Kernel function plays an important role in SVM. At present, the most common kernel functions include:

1 Polynomial kernel function

$$
K(\mathbf{x}, \mathbf{y})=[(\mathbf{x}, \mathbf{y})+1]^{q}
$$

$2 \mathrm{RBF}($ radial basis function) kernel function

$$
K(\mathbf{x}, \mathbf{y})=\exp \left\{-\frac{\|\mathbf{x}-\mathbf{y}\|^{2}}{\sigma^{2}}\right\}
$$

3 Sigmoid kernel function

$$
K(\mathbf{x}, \mathbf{y})=\tanh [\phi(\mathbf{x} \cdot \mathbf{y})+a]
$$

There are many methods to solve quadratic optimization problem of SVM algorithm. The most common methods are the Chunking algorithm, Decomposition algorithm, the SMO algorithm, and Interior point algorithm. Currently, the SMO algorithm is widely applied in the actual problem.

The nonlinear relationship between influence factors and allowable deformation of surrounding rock can be described as $\mathrm{y}=S V M(\mathbf{x})$, where $\mathrm{y}$ is allowable deformation of surrounding rock, $\mathbf{x}=\left(x_{1} x_{2} x_{3}\right)$, and $x_{1}, x_{2}, x_{3}$ are surrounding rock classification, cavern depth and cavern size, respectively. The fitting function of the formula 9 is established through the learning samples. The sketch of the SVM for regression is shown in Fig. 1 .

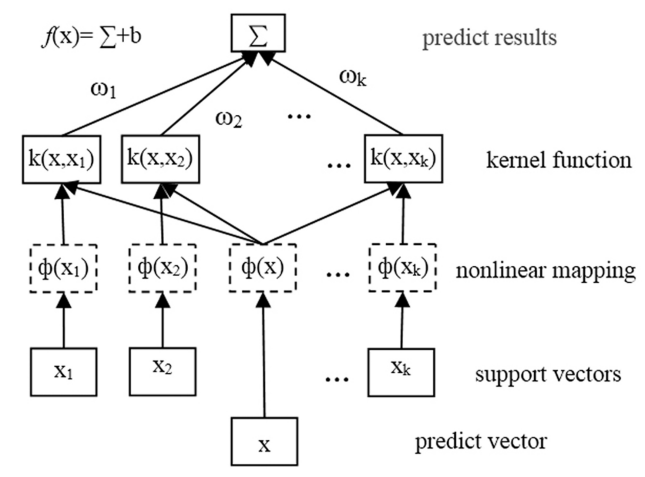

Fig. 1. Schematic representation of the SVM for regression

In the actual projects, most of the underground caverns will be primarily supported immediately after excavation. The deformation data of surrounding rock without a support is quite smaller. Therefore, the deformation of surrounding rock is greatly influenced by the support type.

Allowable deformation prediction of surrounding rock without support was investigated based on the following three steps:

Step 1: The engineering rock mass classification was subdivided based on the national standards Standard for Engineering Classification of Rock Masses (GB50218-94). Meanwhile, more accurate mechanics parameters of surrounding rock were obtained;

Step 2: According to the theory of orthogonal experimental design and genetic algorithm, 100 sets of multi-factors mixed with multi-levels orthogonal experiment were designed. These 100 sets of orthogonal experiment based on the mechanics parameters of surrounding rock, 100 groups of learning samples and 9 samples of random inspection were simulated using ABAQUS. As a result, nonlinear relationship between influence factors and allowable deformation were achieved.

Step 3: The SVM prediction model of allowable deformation was established by investigating of the learning samples based on LibSVM. Moreover, the 9 samples of random inspection and 9 engineering examples were predicted and compared with their actual values.

\section{Rock mass quality classification}

Physical-mechanical parameters of rock mass reflect the stability and quality of rock. These parameters are closely related to hardness degree of rock and rock mass integrity which determine the rock mass basic quality. The national standards Standard for Engineering Classification of Rock Masses (GB50218-94) provides the suggested values of rock mass physical-mechanical parameters at all grades through probability analysis and comprehensive comparison, which is based on many statistical results of experimental data in terms of rock mass quality grade [12]. Rock mass quality classification and 
Tab. 1. Rock mass quality classification and physical-mechanical parameters

\begin{tabular}{|c|c|c|c|c|c|c|}
\hline \multirow{2}{*}{ Basic quality grade } & \multirow{2}{*}{$\begin{array}{c}\text { Gravity } \\
\text { density }\left(\mathrm{kN} / \mathrm{m}^{3}\right)\end{array}$} & \multicolumn{2}{|c|}{ The peak shear strength } & \multirow{2}{*}{$\begin{array}{c}\text { Deformation } \\
\text { modulus } \\
\text { E/GPa }\end{array}$} & \multirow{2}{*}{ Poisson ratio $v$} & \multirow{2}{*}{$\begin{array}{l}\text { Rock mass basic } \\
\text { quality index (BQ) }\end{array}$} \\
\hline & & $\begin{array}{l}\text { Internal friction } \\
\text { angle } \varphi /\left(^{\circ}\right)\end{array}$ & Cohesion C/MPa & & & \\
\hline 1 & $>26.5$ & $>60$ & $>2.1$ & $>33$ & $<0.2$ & $>550$ \\
\hline II & & $60 \sim 50$ & $2.1 \sim 1.5$ & $33 \sim 20$ & $0.2 \sim 0.25$ & $550 \sim 451$ \\
\hline III & $25.4 \sim 24.5$ & $50 \sim 39$ & $1.5 \sim 0.7$ & $20 \sim 6$ & $0.25 \sim 0.3$ & $450 \sim 351$ \\
\hline IV & $24.5 \sim 22.5$ & $39 \sim 27$ & $0.7 \sim 0.2$ & $6 \sim 1.3$ & $0.3 \sim 0.35$ & $350 \sim 251$ \\
\hline V & $<22.5$ & $<27$ & $<0.2$ & $<1.3$ & $>0.35$ & $\leq 250$ \\
\hline
\end{tabular}

Tab. 2. Refinement of rock mass quality classification and physical-mechanical parameters

\begin{tabular}{|c|c|c|c|c|c|c|}
\hline \multirow[t]{2}{*}{ Quality grade } & \multirow{2}{*}{$\begin{array}{c}\text { Gravity density } \\
\left(\mathrm{kN} / \mathrm{m}^{3}\right)\end{array}$} & \multicolumn{2}{|c|}{ The peak shear strength } & \multirow{2}{*}{$\begin{array}{c}\text { Deformation } \\
\text { modulus E /GPa }\end{array}$} & \multirow[t]{2}{*}{ Poisson ratio $v$} & \multirow{2}{*}{$\begin{array}{l}\text { Rock mass basic } \\
\text { quality index (BQ) }\end{array}$} \\
\hline & & $\begin{array}{c}\text { Internal friction } \\
\text { angle } \varphi /\left(^{\circ}\right)\end{array}$ & Cohesion $\mathrm{C} / \mathrm{MPa}$ & & & \\
\hline 2 & 26.5 & 60 & 2.1 & 33 & 0.2 & $550 \sim 517$ \\
\hline 2.33 & & 56.7 & 1.9 & 28.7 & 0.217 & $516 \sim 483$ \\
\hline 2.67 & 26.5 & 53.3 & 1.7 & 24.3 & 0.233 & $484 \sim 451$ \\
\hline 3 & 24.95 & 50 & 1.5 & 20 & 0.25 & $450 \sim 417$ \\
\hline 3.33 & 24.95 & 46.4 & 1.23 & 15.4 & 0.267 & $416 \sim 383$ \\
\hline 3.67 & 24.95 & 42.6 & 0.97 & 10.6 & 0.283 & $384 \sim 351$ \\
\hline 4 & 23.5 & 39 & 0.7 & 6 & 0.3 & $350 \sim 317$ \\
\hline 4.33 & 23.5 & 35 & 0.53 & 4.4 & 0.317 & $316 \sim 283$ \\
\hline 4.67 & 23.5 & 31 & 0.37 & 2.7 & 0.333 & $283 \sim 251$ \\
\hline
\end{tabular}

physical-mechanical parameters are shown in Table 1

The range of values of physical-mechanical parameters is tabulated in Table 1 for the same grade of surrounding rock. Different mechanical parameters in the same grade of surrounding rock will lead to a great difference of surrounding rock deformation when cavern buried depth and cavern size are fixed. The numerical calculation results of surrounding rock deformation have a close relationship to the selection of mechanical parameters, but the influence of each parameter on deformation is different [13]. The research showed that the sensitivities of these parameters affecting deformation in a descending order are the deformation modulus, the internal friction angle, the Poisson ratio, and the cohesion. Especially, the sensitivities of deformation modulus and internal friction angle are comparatively higher than another two parameters [14]. Deformation modulus is the controlling factor which affects the deformation of surrounding rock.

The engineering rock mass classification is subdivided according to rock mass basic quality index $(B Q)$ in order to obtain the allowable deformation more accurately on the basis of surrounding rock grade in preliminary design, as shown in Table 2 .

In the actual projects, surrounding rock of grade II, III, and IV is common. The previous researches showed that rock mass basic quality index $(B Q)$ and physical-mechanical parameters generally meet the linear relationship [15]. Therefore, each grade of surrounding rock was subdivided into three sub-state on the basis of subdivision of rock mass basic quality index $(B Q)$ into three ranges. Also, for grade II, III, and IV rocks, the value of parameters (deformation modulus, internal friction angle, poisson ratio, cohesion) was divided into three equal parts. Then the parameter value on equal diversion point was defined as the representative value of each sub-classification. Since the gravity density has little influence on deformation, the average value of the original gravity density of each surrounding rock grade was used as the representative value of each sub-classification. In this way, the number of quality grade becomes 10 , so the classification relative to original standard is more detailed. Meanwhile, the selection of physical-mechanical parameters of surrounding rock is more reliable, which is beneficial to improve the accuracy of deformation studies.

Currently, classification indexes and grading-standards among various international rock mass classification methods greatly differ. Bieniawski [16] proposed the RMR classification of rock mass mechanics, which has been widely applied. $\mathrm{Xu}$ et al. [17] studied the relationship between $B Q$ and $R M R$, and suggested a modified empirical formula as follows:

$$
B Q=170 \ln \frac{15+0.24 R M R}{5.7-0.06 R M R}
$$

Relationship between $B Q$ and $R M R$ can be obtained by Eq. (1). For foreign rock mass engineering, the new classification can be determined according to value range of $B Q$ in Table 2, and the corresponding physical-mechanical parameters will be acquired. The successful experience of foreign engineer- 
ing design based on rock mass classification provides insights in the design and investigations. Allowable deformation of the foreign underground caverns can also be predicted at the same time.

\section{Numerical simulation experiment}

\subsection{Orthogonal design}

In the actual projects, rock mass quality of - grade V surrounding rock is worse. Deformation of caverns develops as soon as the excavation is carried out and becomes larger if primary support is not made immediately after excavation. Quality grade was divided into 10 categories as shown in Table 2. Cavern depth was considered up to $500 \mathrm{~m}$ and cavern radius was controlled from $1.5 \mathrm{~m}$ to $6 \mathrm{~m}$. The cavern depth and radius of $\mathrm{V}$ grade surrounding rock range to the large value which ultimately lead to the failure. Therefore, V-grade surrounding rock was not considered in this study. The orthogonal factor level of numerical simulation experiment is shown in Table 3 .

Tab. 3. Orthogonal factor level table

\begin{tabular}{cccc}
\hline Factor & \multicolumn{3}{c}{ Experiment level } \\
\cline { 2 - 4 } & Quality grade & Cavern depth / m & Cavern radius $/ \mathrm{m}$ \\
\hline 1 & 2 & 50 & 1.5 \\
\hline 2 & 2.33 & 100 & 2 \\
\hline 3 & 2.67 & 150 & 2.5 \\
\hline 4 & 3 & 200 & 3 \\
\hline 5 & 3.33 & 250 & 3.5 \\
\hline 6 & 3.67 & 300 & 4 \\
\hline 7 & 4 & 350 & 4.5 \\
\hline 8 & 4.33 & 400 & 5 \\
\hline 9 & 4.67 & 450 & 5.5 \\
\hline 10 & $/$ & 500 & 6 \\
\hline
\end{tabular}

According to Table 3, 900 groups of experiment were to be carried out if test was conducted comprehensively. Therefore, the scale would be very large. Fortunately, orthogonal experiment design method is an effective method which makes scientific arrangement and solves the problem of multi-factors experiment using "orthogonal table".

As the levels of each factor were large and unequal in simulation experiment design, standard orthogonal table would not meet the requirements. Yang et al. [18] solved the large-scale multi-factors mixed with multi-levels experiment design problem, which, however, did not agree to the standard orthogonal table based on orthogonal design theory, taking genetic algorithms as optimization algorithms. A reasonable experimental scheme was proposed in this paper. In this study, 100 groups of experiments were designed as the numerical simulation experiment scheme using the above method, and were sorted according to the quality grade of surrounding rock. Due to limitations of space, 20 of them are listed as representative in Table 4.

\subsection{Numerical simulation}

Two-dimensional numerical model was established for numerical calculation based on ABAQUS [19]. The surrounding rock ranging about 3 to 5 times the tunnel diameter from the center of the excavation scope was affected by the tunnel excavation [20]. In order to eliminate the influence of the boundary effect on the calculation results, the calculation range was determined. The left, right and down boundaries were more than six times of cavern diameter from the cavern boundary. It is noted that the upper boundary was at the actual distance to the surface. And the boundary from the center of tunnel was $80 \mathrm{~m}$. The left and right boundaries were set to horizontal restraint. The bottom boundary was set to vertical restraint while the upper boundary was free surface. A total of 100 groups of orthogonal experiment models and 9 experiment models of random inspection were established. The 9 samples of random inspection were randomly selected. The representative numerical model is shown in Fig.2.

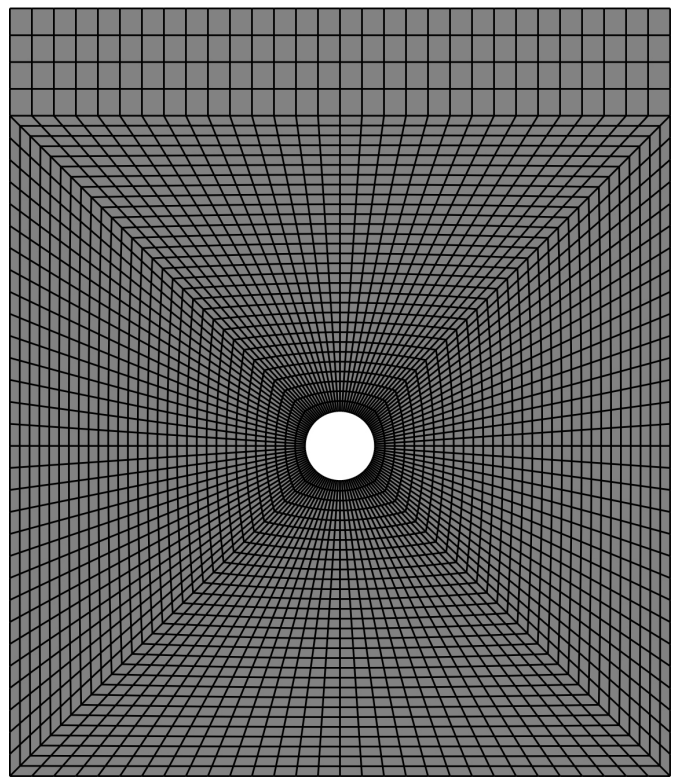

Fig. 2. Representative numerical model

In the calculation process, Mohr-Coulomb failure criterion was adopted. The lateral pressure coefficient was $v /(1-v)$, and dilatancy angle was half of the internal friction angle [21]. Other physical-mechanical parameters were selected in accordance to Table 2. Gravity stress of rock mass was exerted to the entire model.

\subsection{Numerical simulation results}

In the numerical simulation experiment, the allowable deformation is the maximum displacement of caverns just before failure. 100 groups of numerical simulation experiments were carried out using the above models. As a result, 100 groups of allowable deformation of surrounding rock of underground caverns were obtained and thus, the learning samples of SVM prediction model were obtained. Due to limitations of space, 20 of them are listed as representative in Table 5 Meanwhile, cavern depth range was considered within $500 \mathrm{~m}$ and cavern ra- 
Tab. 4. Representative orthogonal experimental scheme

\begin{tabular}{|c|c|c|c|c|c|c|c|}
\hline Experiment No. & Quality grade & $\begin{array}{c}\text { Cavern depth } \\
\text { (m) }\end{array}$ & $\begin{array}{c}\text { Cavern radius } \\
(\mathrm{m})\end{array}$ & Experiment No. & Quality grade & $\begin{array}{c}\text { Cavern depth } \\
(\mathrm{m})\end{array}$ & $\begin{array}{c}\text { Cavern radius } \\
\text { (m) }\end{array}$ \\
\hline 5 & 2 & 250 & 3 & 55 & 3.33 & 100 & 5.5 \\
\hline 15 & 2.33 & 200 & 4.5 & 65 & 3.67 & 300 & 3.5 \\
\hline 20 & 2.33 & 300 & 6 & 70 & 4 & 250 & 3.5 \\
\hline 25 & 2.67 & 350 & 1.5 & 75 & 4 & 450 & 5.5 \\
\hline 30 & 2.67 & 500 & 4 & 80 & 4.33 & 150 & 2.5 \\
\hline 35 & 3 & 250 & 3 & 85 & 4.33 & 50 & 2 \\
\hline 40 & 3 & 500 & 3.5 & 90 & 4.67 & 250 & 2.5 \\
\hline 45 & 3.33 & 300 & 4 & 95 & 4.67 & 50 & 2.5 \\
\hline 50 & 3.33 & 350 & 2.5 & 100 & 4.67 & 450 & 4 \\
\hline
\end{tabular}

dius ranged from $1.5 \mathrm{~m}$ to $6 \mathrm{~m}$. The cavern depth and cavern radius were selected randomly based on these criteria according to grade quality. 9 groups of random numerical simulation experiments were carried out in total, and the experiment results were taken as inspection samples.

\section{Allowable deformation prediction of surrounding rock based on SVM}

\subsection{Allowable deformation prediction of surrounding rock}

Many commercial packs of software are available currently for the calculation of SVM. In this paper, the calculation was carried out based on LibSVM [22]. RBF kernel function was selected as the kernel function of calculation model which had a good fitting and generalization capability. SMO algorithm was used to solve the quadratic optimization problem. The key parameters of SVM model were penalty coefficient $C$ and RBF kernel function parameter $\sigma^{2}$.

In order to eliminate the influence of large difference of values and inconsistent dimension among three influence factors, all factors were normalized to the interval $[0,1]$ before sample learning. The learning process was actually the process of finding the optimal model parameters $C$ and $\sigma^{2}$. Parameter selection has much influence on the prediction results. Cross-validation method was used to select the parameters $C$ and $\sigma^{2}$. Firstly, the range of value of parameters $C$ and $\sigma^{2}$ was determined. Secondly, the chosen parameter was combined and the learning samples were trained. Finally, the optimal parameters of SVM model were obtained. The optimal model parameters obtained after calculation are $C=94$ and $\sigma^{2}=0.5$.

Then, 100 learning samples were trained using the optimal model parameter $\mathrm{C}$ and $\sigma^{2}$. The $b$ value of 20.122 and 74 groups of support vector were obtained from the trained results. The values of Lagrange multipliers of 74 groups of support vector are shown in Table 6.

At this point, the SVM prediction model of surrounding rock was established. The allowable rock deformation could be predicted from Eq. (9) and Fig. 1.

The 9 samples of random assessment were anticipated by utilizing the established SVM prediction model as demonstrated in Table 7 The comparison of numerical simulation values and prediction values by SVM is presented in Fig. 3 It can be seen from Table 7 and Fig. 3, the maximum relative error of the SVM prediction is $8.8 \%$. The error is small and the SVM prediction model has a decent prediction effect. Therefore, SVM can be used to predict the allowable deformation of surrounding rock with high accuracy and great applicability.

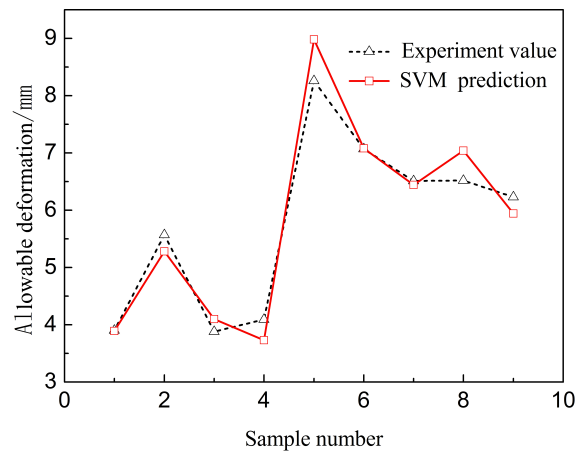

Fig. 3. Comparison of numerical simulation values and prediction values by SVM

\subsection{Engineering example verification}

The study demonstrates that SVM has good relevance in allowable deformation for surrounding rock of underground caverns. Since the learning samples were obtained by numerical simulation experiment, it is not clear whether the SVM prediction model can be utilized to predict the allowable deformation for surrounding rock of actual underground caverns well. Therefore, engineering examples were selected to validate the SVM prediction model. The underground caverns which have smaller tectonic stress (particularly horizontal stress) and no primary support were selected as engineering examples the extent that this would be possible. In total, nine engineering examples were selected for validation [4].

For the nine engineering examples, rock mass classification was subdivided according to rock mass basic quality index $(B Q)$ as shown in Table 2 If $B Q$ was not obtained, rock mass clas- 
Tab. 5. Representative experimental results

\begin{tabular}{cccc}
\hline Experiment No. & $\begin{array}{c}\text { Allowable } \\
\text { deformation }(\mathrm{mm})\end{array}$ & Experiment No. & $\begin{array}{c}\text { Allowable } \\
\text { deformation }(\mathrm{mm})\end{array}$ \\
\hline 5 & 1.54 & 55 & 2.16 \\
\hline 10 & 1.20 & 60 & 11.31 \\
\hline 15 & 2.14 & 65 & 5.98 \\
\hline 20 & 4.44 & 70 & 8.50 \\
\hline 25 & 1.39 & 75 & 32.89 \\
\hline 30 & 5.59 & 80 & 4.45 \\
\hline 35 & 2.30 & 85 & 1.20 \\
\hline 40 & 5.47 & 90 & 15.88 \\
\hline 45 & 4.81 & 95 & 2.43 \\
\hline 50 & 3.42 & 100 & 114.81 \\
\hline
\end{tabular}

Tab. 6. Values of Lagrange multipliers of SVM prediction model

\begin{tabular}{|c|c|c|c|c|c|c|c|c|c|c|c|c|c|c|}
\hline No. & $\alpha$ & $\alpha^{*}$ & No. & $\alpha$ & $\alpha^{*}$ & No. & $\alpha$ & $\alpha^{*}$ & No. & $\alpha$ & $\alpha^{*}$ & No. & $\alpha$ & $\alpha^{*}$ \\
\hline 1 & 94.000 & 0.000 & 16 & 0.000 & 20.433 & 31 & 0.000 & 18.003 & 46 & 0.000 & 28.570 & 61 & 0.000 & 94.000 \\
\hline 2 & 0.000 & 8.857 & 17 & 4.078 & 0.000 & 32 & 76.262 & 0.000 & 47 & 94.000 & 0.000 & 62 & 70.908 & 0.000 \\
\hline 4 & 94.000 & 0.000 & 19 & 0.000 & 94.000 & 34 & 0.000 & 47.437 & 49 & 0.000 & 94.000 & 64 & 54.156 & 0.000 \\
\hline 5 & 0.000 & 0.872 & 20 & 94.000 & 0.000 & 35 & 0.000 & 17.140 & 50 & 94.000 & 0.000 & 65 & 94.000 & 0.000 \\
\hline 6 & 0.000 & 61.553 & 21 & 0.000 & 94.000 & 36 & 0.000 & 94.000 & 51 & 39.143 & 0.000 & 66 & 94.000 & 0.000 \\
\hline 7 & 0.000 & 8.164 & 22 & 94.000 & 0.000 & 37 & 31.325 & 0.000 & 52 & 10.295 & 0.000 & 67 & 94.000 & 0.000 \\
\hline 8 & 41.439 & 0.000 & 23 & 94.000 & 0.000 & 38 & 42.379 & 0.000 & 53 & 0.000 & 94.000 & 68 & 39.363 & 0.000 \\
\hline 9 & 1.233 & 0.000 & 24 & 0.000 & 93.409 & 39 & 94.000 & 0.000 & 54 & 0.000 & 94.000 & 69 & 0.000 & 73.266 \\
\hline 10 & 36.894 & 0.000 & 25 & 94.000 & 0.000 & 40 & 94.000 & 0.000 & 55 & 0.000 & 94.000 & 70 & 94.000 & 0.000 \\
\hline 11 & 0.000 & 22.154 & 26 & 35.037 & 0.000 & 41 & 0.000 & 94.000 & 56 & 0.000 & 81.111 & 71 & 0.000 & 73.784 \\
\hline 12 & 20.883 & 0.000 & 27 & 0.000 & 41.761 & 42 & 0.000 & 8.001 & 57 & 0.000 & 39.606 & 72 & 94.000 & 0.000 \\
\hline 14 & 0.000 & 14.046 & 29 & 94.000 & 0.000 & 44 & 0.000 & 94.000 & 59 & 0.000 & 94.000 & 74 & 94.000 & 0.000 \\
\hline 15 & 0.000 & 94.000 & 30 & 94.000 & 0.000 & 45 & 10.773 & 0.000 & 60 & 0.000 & 94.000 & & & \\
\hline
\end{tabular}

sification was subdivided according to the sequences of sensitivity to deformation, being the deformation modulus, the internal friction angle, the Poisson ratio, and the cohesion in a decreasing order. An equivalent radius of a quarter of the aggregate of height and span was used to represent actual size of caverns for the non-circular caverns in engineering applications. Cavern buried depth, quality grade and cavern radius that had been changed over were substituted into the SVM prediction model as influence factors. Allowable deformation of surrounding rock was predicted as presented in Table 8 . The correlation of measured values and prediction values by SVM was demonstrated in Fig. 4. It can be seen from Table 8 and Fig. 4 that the prediction values of allowable deformation by SVM concurred well with the measured values for the nine engineering examples. The maximum relative error is $20 \%$. Since the engineering measured values are influenced by the inevitable tectonic stress and measurement error, it is believed that predictions can meet the engineering prerequisites well for the preliminary design of underground caverns.

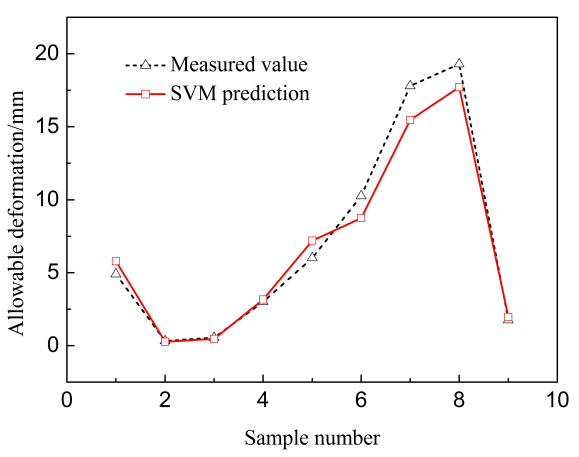

Fig. 4. Comparison of measured values and prediction values by SVM

\section{Application research in engineering}

In the preliminary design of underground caverns, if $B Q$ and detailed physical-mechanical parameters of surrounding rock are not obtained, allowable deformation can be predicted according to geological characteristics of rock mass in the engineering area. Initially, the basic quality grade in which the rock mass belongs to in the National Standards on the basis of actual geological conditions is figured out. Then, according to 
Tab. 7. Prediction test for allowable deformation of surrounding rock

\begin{tabular}{|c|c|c|c|c|c|c|}
\hline Experiment No. & Quality grade & Cavern depth (m) & Cavern radius (m) & $\begin{array}{c}\text { Experiment } \\
\text { Deformation }(\mathrm{mm})\end{array}$ & $\begin{array}{c}\text { Prediction } \\
\text { Deformation }(\mathrm{mm})\end{array}$ & Relative error/ \% \\
\hline 1 & 2 & 380 & 4.8 & 3.90 & 3.89 & 0.26 \\
\hline 3 & 2.67 & 390 & 3.6 & 3.88 & 4.1 & 5.67 \\
\hline 4 & 3 & 310 & 4.2 & 4.09 & 3.73 & 8.80 \\
\hline 5 & 3.33 & 420 & 4.8 & 8.26 & 8.98 & 8.72 \\
\hline 6 & 3.67 & 230 & 5.2 & 7.07 & 7.08 & 0.14 \\
\hline 7 & 4 & 220 & 3.2 & 6.51 & 6.44 & 1.08 \\
\hline 8 & 4.33 & 180 & 2.8 & 6.52 & 7.04 & 7.98 \\
\hline 9 & 4.67 & 130 & 2.3 & 6.23 & 5.94 & 4.65 \\
\hline
\end{tabular}

Tab. 8. Engineering examples showing an allowable deformation prediction for surrounding rock

\begin{tabular}{|c|c|c|c|c|c|c|c|}
\hline No. & Engineering name & $\begin{array}{c}\text { Quality } \\
\text { grade }\end{array}$ & $\begin{array}{c}\text { Cavern } \\
\text { depth }(m)\end{array}$ & $\begin{array}{c}\text { Cavern } \\
\text { radius }(\mathrm{m})\end{array}$ & $\begin{array}{c}\text { Measured } \\
\text { deformation } \\
(\mathrm{mm})\end{array}$ & $\begin{array}{l}\text { Prediction } \\
\text { deformation } \\
(\mathrm{mm})\end{array}$ & $\begin{array}{l}\text { Relative } \\
\text { error (\%) }\end{array}$ \\
\hline 2 & Diversion tunnel from Fuerjiang J2 & 2 & 78 & 1.95 & 0.32 & 0.26 & 18.8 \\
\hline 3 & Lubuge experimental cavity $0+25.18$ & 2 & 175 & 1.9 & 0.55 & 0.46 & 16.4 \\
\hline 4 & Leigongjian tunnel $1984+150.85$ & 3.67 & 110 & 5.3 & 3 & 3.16 & 5.3 \\
\hline 5 & Xishimen primary crusher chamber & 3.67 & 206 & 5.738 & 6 & 7.2 & 20 \\
\hline 6 & Hebi No.4 Mine & 4.33 & 350 & 1.775 & 10.26 & 8.74 & 14.8 \\
\hline 7 & Xiaoguanzhuang air-return roadway & 4.67 & 450 & 1.675 & 17.8 & 15.47 & 13.1 \\
\hline 8 & Xiaoguanzhuang transportation tunnel & 4.67 & 550 & 1.675 & 19.3 & 17.72 & 8.2 \\
\hline 9 & Bayilin tunnel $9+749$ & 3.33 & 114 & 4.3 & 1.76 & 1.96 & 11.4 \\
\hline
\end{tabular}

the qualitative characteristics of rock mass, the quality of the rock mass is chosen whether it is in great, reasonable or poor condition in the basic quality grade corresponding to the three sub-classifications in Table 2 Once the quality grade is determined, allowable deformation of surrounding rock for proposed underground caverns can be predicted by using the established SVM prediction model. The results can provide reference for preliminary design of underground caverns, even for project site selection.

Because of the larger range of cavern depth and radius in this study, the caverns in V-grade surrounding rock have large deformation or even might have reached failure. Thus, V-grade surrounding rock was not considered. For the V-grade surrounding rock, we can contract the range of cavern depth and cavern radius. Then, the learning samples for $\mathrm{V}$-grade surrounding rock can be obtained by numerical simulation experiment emulating the research method of this study. The SVM prediction model for V-grade surrounding rock will be established finally.

However, for the large-span deep caverns, the value range of cavern depth and cavern radius in this study is not sufficient. Geostress situation in the engineering area where the location of these caverns is complex and uncertain, the influence of tectonic stress must be considered for the learning samples used to establish the SVM prediction model. Therefore, the prediction model in this study is not suitable for the large-span deep caverns. Further research is required in the following work for this case.

In conclusion, for the general underground caverns whose buried depth is less than $500 \mathrm{~m}$ and cavity diameter is less than $12 \mathrm{~m}$. When they have smaller tectonic stress, the SVM prediction model that had been created in this study has a good applicability. Once the quality grade of surrounding rock, cavern buried depth and cavern radius were determined, the allowable deformation would be obtained quickly and conveniently based on the SVM prediction model. In the meantime, the prediction accuracy is high and the maximum relative error is $20 \%$. It is believed that predictions can meet the engineering requirements well so that the support design can be outlined in the preliminary design stage of underground caverns.

\section{Conclusions}

Following conclusions can be drawn from this study:

1 The engineering rock mass classification was subdivided based on the national standards, Standard for Engineering Classification of Rock Masses (GB50218-94). According to the new classification, the selection of physical-mechanical parameters of surrounding rock is more reliable, which is beneficial to improve the accuracy of deformation prediction. According to the new classification, the selection of physicalmechanical parameters of surrounding rock was more reliable, which proved to be advantageous in enhancing the accuracy of deformation prediction. 
2 Two-dimensional numerical models were established based on ABAQUS to simulate 100 sets of multi-factors and multilevels orthogonal experiments in which the more accurate physical-mechanical parameters of surrounding rock were utilized. Thereafter, 100 groups of learning samples and 9 samples of random inspection were obtained. These samples ultimately overcome the influence of supporting type, tectonic stress, rock mass classification and measurement error.

3 The SVM prediction model of allowable deformation was established. The optimal model parameter $\mathrm{C}$ was 94 and $\sigma^{2}$ was 0.5. The 9 samples of random inspection were predicted by using the SVM prediction model created in this study. Then the prediction results were compared with the experiment values. The results demonstrated that the prediction accuracy was high. The maximum relative error of the SVM prediction was $8.8 \%$. The SVM prediction model created in this study had the advantages of comfort, rate, and reliability.

4 Allowable deformation of surrounding rock for 9 engineering examples was predicted by using the established SVM prediction model. The results showed that the prediction values agreed well with the measured values and the maximum relative error was $20 \%$. Since the engineering measured values are influenced by the inevitable tectonic stress and measurement error, it is believed that predictions can meet the engineering prerequisites well for the preliminary design of underground caverns.

\section{Acknowledgements}

This study is financially supported by nuclear wastes major project of the State Administration of Science, Technology and Industry for National Defense (SASTIND).

\section{References}

1 Kontogianni V A, Stiros S C, Predictions and observations of convergence in shallow tunnels: Case histories in Greece, Engineering Geology, 63(3), (2002), 333-345, DOI 10.1016/S0013-7952(01)00094-1

2 Li S J, Zhao H B, Ru Z L, Deformation prediction of tunnel surrounding rock mass using CPSO-SVM model, Journal of Central South University, 19(11), (2012), 3311-3319, DOI 10.1007/s11771-012-1409-3

3 Li X B, Wang Q S, Yao J R, Zhao G Y, Chaotic time series prediction for surrounding rock's deformation of deep mine lanes in soft rock, Journal of Central South University, 15(2), (2008), 224-229, DOI 10.1007/s11771-0080043-6

4 Li S H, A New Concept of Tunnel Support Design - Application and Theory of Precedent Type Analysis, Science Press; Beijing, 1999.

5 Yang Z W, Deformation prediction of surrounding rock mass of underground cavern, East China Hydropower Technology, 2, (1990), 1-13.

6 Vapnik VN, The Nature of Statistical Learning Theory, 2nd edition, Springer; New York, 1995.

7 Cortee C, Vapnik V, Support Vector Networks, Machine Learning, 20(2), (1995), 273-297, DOI 10.1023/A:1022627411411

8 Anthony T C G, Goh S H, Support vector machines: Their use in geotechnical engineering as illustrated using seismic liquefaction data, Computers and Geotechnics, 34(5), (2007), 410-421, DOI 10.1016/j.compgeo.2007.06.001
9 Feng X T, Zhao H B, Li S J, Modeling non-linear displacement time series of geo-materials using evolutionary support vector machines, International Journal of Rock Mechanics and Mining Sciences, 41(7), (2004), 1087-1107, DOI 10.1016/j.ijrmms.2004.04.003

10 Zhao H B, Ru Z L, Yin S D, Updated support vector machine for seismic liquefaction evaluation based on the penetration tests, Marine Georesources \& Geotechnology, 25(3), (2008), 209-220, DOI 10.1080/10641190701702303

11 Smola A J, Scholkopf B, A tutorial on support vector regression, Statistics and Computing, 14(3), (2004), 199-222, DOI 10.1023/B:STCO.0000035301.49549.88

12 The National Standards Compilation Group of People's Republic of China, GB50218-1994, Standard for Engineering Classification of Rock Masses, China Planning Press; Beijing, 1995.

13 Beiki M, Bashari A, Majdi A, Genetic programming approach for estimating the deformation modulus of rock mass using sensitivity analysis by neural network, International Journal of Rock Mechanics and Mining Sciences, 47(1), (2010), 1091-1103, DOI 10.1016/j.ijrmms.2010.07.007

14 Hou S H, Li X, Wang S J, Lu S B, Sensitivity analysis of mechanical parameters to deformation of surrounding rocks for a tunnel in JIN CHUAN Deposit II, Chinese Journal of Rock Mechanics and Engineering, 24(3), (2005), 406-410.

15 Xu H F, Zhou J M, Wu H J, Simplified method for national standard for engineering classification of rock mass, Rock and Soil Mechanics, 26(S), (2005), 88-90.

16 Bieniawski Z T, Engineering Rock Mass Classifications, The WileyInterscience Publication; New York, 1989.

17 Xu H F, Chen F, Wang B, Hua Z M, Geng H S, Relationships between $R M R$ and $B Q$ for rock mass classification and estimation of its mechanical parameters, Chinese Journal of Geotechnical Engineering, 36(1), (2014), 195-198, DOI 10.11779/CJGE201401021

18 Yang C W, Cong P S, Zhu Z J, Wu D, Zhang L G, Lu Y M, An easy programming and intuitionistic experimental design strategy for large sample systems, Computers and Applied Chemistry, 25(6), (2008), 668-670.

19 ABAQUS/standard user's manuals v61, Hibbitt, Karlsson and Sorensen Inc, 2010.

20 Hoek E, Brown E T, Underground Excavation in Rock, the Institute of Mining and Metallurgy; London, 1980.

21 Kong W X, Rui Y Q, Dong B D, Determination of dilatancy angle for geomaterials under non-associated flow rule, Rock and Soil Mechanics, 30(11), (2009), 3278-3282.

22 Chang C C, Lin C J, LIBSVM: a library for support vector machines, ACM Transactions on Intelligent Systems and Technology, 2(3), (2011), 1-39, DOI $10.1145 / 1961189.1961199$ 